\title{
RNA-sequencing Analysis Identifies Genes Associated with Chilling-mediated Endodormancy Release in Apple
}

\author{
Takanori Takeuchi ${ }^{1}$, Miwako Cecile Matsushita ${ }^{1}$, Soichiro Nishiyama ${ }^{1}$, and Hisayo Yamane ${ }^{2}$ \\ Graduate School of Agriculture, Kyoto University, Kyoto 606-8502, Japan
}

Kiyoshi Banno
Faculty of Agriculture, Shinshu University, Minami-Minowa, Kami-Ina 299-4511, Japan

Ryutaro Tao

Graduate School of Agriculture, Kyoto University, Kyoto 606-8502, Japan

AdDitional INDEX wORDs. bud dormancy, chilling requirement, global warming, MADS-box, Malus transcription factor

\begin{abstract}
Endodormancy release and the fulfillment of the chilling requirement (CR) are critical physiological processes that enable uniform blooming in fruit tree species, including apple (Malus $\times$ domestica). However, the molecular mechanisms underlying these traits have not been fully characterized. The objective of this study was to identify potential master regulators of endodormancy release and the CR in apple. We conducted RNA-Sequencing (RNA-seq) analyses and narrowed down the number of candidates among the differentially expressed genes (DEGs) based on the following two strict screening criteria: 1) the gene must be differentially expressed between endodormant and ecodormant buds under different environmental conditions and 2) the gene must exhibit chill unit (CU)correlated expression. The results of our cluster analysis suggested that global expression patterns varied between field-grown buds and continuously chilled buds, even though they were exposed to similar amounts of chilling and were expected to have a similar dormancy status. Consequently, our strict selection strategy resulted in narrowing down the number of possible candidates and identified the DEGs strongly associated with the transition between dormancy stages. The genes included four transcription factor genes, PHYTOCHROME-INTERACTING FACTOR 4 (PIF4), FLOWERING LOCUS C (FLC)-LIKE, APETALLA2 (AP2)/ETHYLENE-RESPONSIVE 113 (ERF113), and $M Y C 2$. Their expressions were upregulated during endodormancy release, and were correlated with the $C U$, suggesting that these transcription factors are closely associated with chilling-mediated endodormancy release in apple.
\end{abstract}

Perennial woody plants in temperate regions modulate their growth rhythm to adapt to seasonal environmental changes. For example, bud dormancy is an adaptive mechanism that enables buds to survive unfavorable conditions, such as low temperatures during winter. Bud dormancy can be fundamentally defined as the inability of the meristem to resume growth under favorable conditions (Rohde and Bhalerao, 2007). Lang (1987) and Lang et al. (1987) classified the physiological states of dormant buds into the following three types: para, endo-, and ecodormancy. Paradormancy is also known as correlative inhibition and is induced by signals produced in other parts of a growing plant. Endodormancy refers to a suspension of growth due to internal factors within the meristem-containing tissue. Endodormancy establishment is controlled by environmental cues, such as low temperatures and a short photoperiod (Maurya and Bhalerao, 2017; Olsen, 2010). A previous study revealed that low temperatures are the only requirement for endodormancy establishment in apple (Heide and Prestrud, 2005). Endodormant buds are incapable of resuming growth until they are exposed to a specific chilling period (i.e., CR), which is genetically determined. After the $\mathrm{CR}$ has been

Received for publication 16 Jan. 2018. Accepted for publication 11 Apr. 2018. This work was supported by a Grant-in-Aid for Scientific Research (A) from the Japan Society for the Promotion of Science (JSPS KAKENHI grant number 26252005) to H.Y.

${ }^{1}$ These authors contributed equally.

${ }^{2}$ Corresponding author. E-mail: hyamane@kais.kyoto-u.ac.jp. satisfied, buds are released from endodormancy and shifted to ecodormancy, in which growth is inhibited by external environmental factors, such as cold and drought conditions. Despite these dormancy classifications, it is difficult to qualitatively discriminate between phases because there is some overlap between each phase. Thus, we currently cannot precisely distinguish between endodormancy and ecodormancy in trees.

Bud dormancy release and CR fulfillment are agronomically important physiological steps that influence flowering time and the subsequent fruit production. Dormancy-related flowering disorders (e.g., nonuniform flowering and bud abortion) that inhibit fruit production have been observed in many species and are believed to have been caused, at least in part, by insufficient endodormancy release putatively due to global warming (Sugiura et al., 2007). Consequently, the genetic factors and the molecular network underlying endodormancy release should be elucidated. A thorough characterization of the molecular basis of endodormancy release may enable the artificial control of endodormancy through cultural practices. It may also be relevant for efficient breeding (e.g., markerassisted selection).

The molecular regulation of endodormancy has recently been widely studied in many species, including poplar (Populus sp.), which is a model perennial woody plant (Cooke et al., 2012; Maurya and Bhalerao, 2017; Rinne et al., 2010; Ruttink et al., 2007). In poplar, the CONSTANS (CO)/FLOWERING LOCUS $\mathrm{T}$ (FT) module, which is critical for flowering in arabidopsis 
(Arabidopsis thaliana), is involved in short photoperiod-induced growth cessation and bud set (Böhlenius et al., 2006). Hsu et al. (2011) reported that there are two FT genes with distinct roles affecting development. Rohde et al. (2011) identified six robust quantitative trait loci (QTLs) for time to bud set in four different pedigrees, and FT colocalized with one of these QTLs. In addition, FT expression is hyperinduced during chillinginduced dormancy release in poplar (Rinne et al., 2011), suggesting that $F T$ is involved in both dormancy establishment and release. In addition, $F T$ reportedly affects dormancy in grapevine (Vitis sp.) (Pérez et al., 2011). Other genes potentially affecting dormancy are DORMANCY-ASSOCIATED MADS$B O X(D A M)$ genes, which belong to the SHORT VEGETATIVE PHASE (SVP)/AGAMOUS-LIKE 24 (AGL24) clade. The DAM genes were first identified as candidate genes in the evergrowing (evg) peach (Prunus persica) mutant incapable of entering dormancy (Bielenberg et al., 2008). The evg mutant continues to grow even under dormancy-inducing conditions and exhibits a loss of transcriptional activity of six tandemly arrayed $D A M$ genes ( $D A M 1-6)$. The peach $D A M$ gene expression levels were observed to be upregulated during endodormancy induction and downregulated during endodormancy release toward budbreak (Li et al., 2009; Yamane et al., 2011a, 2011b), suggesting these genes may influence dormancy progression and budbreak. In addition, a strong QTL for the CR and blooming date in peach was detected in the region near the $E V G$ locus (Fan et al., 2010). Moreover, the possible involvement of SVP-like genes in either endodormancy induction or release was also reported for other perennial species, such as japanese apricot [Prunus mume (Kitamura et al., 2016; Sasaki et al., 2011; Yamane et al., 2008)], japanese pear [Pyrus pyrifolia (Ito et al., 2016; Saito et al., 2013; Ubi et al., 2010)], kiwifruit [Actinidia sp. (Wu et al., 2012)], raspberry [Rubus idaeus (Mazzitelli et al., 2007)], and leafy spurge [Euphorbia esula (Horvath et al., 2008)]. In apple, several $D A M$-like genes have been cloned, although different research groups have used different names for the same genes (Mimida et al., 2015; Porto et al., 2016; Wisniewski et al., 2015). Porto et al. (2016) proposed that the 'Golden Delicious' apple genome contains four $D A M$-like genes ( $M d D A M 1-4)$. Expression analyses suggest that the $M d D A M$ genes undergo seasonal expression-level changes, with an upregulation during endodormancy (Kumar et al., 2016a; Mimida et al., 2015; Porto et al., 2016; Wisniewski et al., 2015). However, in apple, the downregulated expression of $M d D A M$ genes does not appear to be associated with the CR for endodormancy release (Mimida et al., 2015; Porto et al., 2016; Yamane et al., 2018), which is in contrast to Prunus species in which the downregulated expression levels of some $D A M$ genes are associated with the genotypedependent CR (Leida et al., 2012; Li et al., 2009; Sasaki et al., 2011; Yamane et al., 2011a, 2011b). The expression level of $M d D A M 1$, which is the most highly expressed among all $M d D A M$ genes, is relatively high even during endodormancy release but is subsequently downregulated during the budbreak stage (Mimida et al., 2015; Porto et al., 2016; Yamane et al., 2018). A recent finding that the ectopic expression of $M d D A M b$, which is one of the $S V P / D A M$-like genes other than $M d D A M 1-4$, delays budbreak (Wu et al., 2017) suggests that $D A M$ genes help regulate budbreak in both apple and Prunus species However, previously reported endogenous expression analyses suggest that apple $D A M$ genes may not be critical for endodormancy release.

Apple is one of the most important fruits in Japan and globally. Apple trees have adapted to survive in the relatively cool climates of temperate regions. In Japan, apple flower buds differentiate in early summer and enter endodormancy in autumn, which is followed by a gradual shift to ecodormancy in midwinter. The effects of global warming may change where apple can be cultivated (i.e., more northern regions) and decrease apple production because of a dormancy-related disorder, which has already been observed in Brazil (Petri and Leite, 2004) and South Africa (Labuschagné et al., 2002). One characteristic of apple dormancy is that endodormancy is induced in response to low temperatures, but not to a short photoperiod (Heide and Prestrud, 2005), suggesting that the associated regulatory mechanism differs from that of other species that enter dormancy in response to a short photoperiod, such as poplar and peach. To date, apple dormancy has been studied from various perspectives, such as physiological and molecular changes (Porto et al., 2015; Wang et al., 1991; Wisniewski et al., 2015) as well as genetic analyses (Celton et al., 2011; van Dyk et al., 2010). All of these transcriptome studies involved the heterozygous 'Golden Delicious' apple genome (Velasco et al., 2010). However, the genome sequence of a homozygous GDDH13 doubled-haploid apple line was recently published (Daccord et al., 2017). The estimated number of apple genes has decreased from 63,541 in the original apple genome (Velasco et al., 2010) to 42,140 in the new apple reference genome (Daccord et al., 2017), and many overlapping genes have been filtered out. A transcriptome analysis using the new apple reference genome may enable more accurate mapping, ultimately resulting in a more precise identification of DEGs and gene ontology (GO) analysis. However, RNA-seq studies focused on apple dormancy have not been conducted using the new version of the apple genome.

The objective of the present study was to identify candidate master regulators responsible for controlling endodormancy release, such as DAM genes in Prunus species. So far, published transcriptome analyses of apple dormancy involving microarrays (Porto et al., 2015) or RNA-Seq (Kumar et al., 2016a) detected many DEGs as potential regulators of dormancy. In this study, we aimed to identify genes strongly associated with endodormancy release by narrowing down the number of candidates using a unique strategy. We applied the following strategy: 1) we sequenced mRNAs derived from samples exposed to several environmental conditions and collected an appropriate number of biological replications for each sampling date to enable statistical analyses; 2) we set two strict screening criteria: 1) the gene should be differentially expressed in the buds between endodormancy $(0 \%$ budbreak under forcing conditions) and ecodormancy (100\% budbreak under forcing conditions) and 2) the expression of the gene should be correlated with the $\mathrm{CR}$ for endodormancy release. We first conducted a cluster analysis to observe global gene expressionlevel changes in dormant buds under different environmental conditions. We then narrowed down the possible DEGs and identified a few transcription factors, candidates for potential master regulators of dormancy release in apple.

\section{Materials and Methods}

Plant material. This study was completed using six mature 'Fuji' apple trees grown at the experimental farm of the Department of Agriculture, Shinshu University (Nagano, Japan; $36^{\prime} \mathrm{N}$ and $\left.139^{\prime} \mathrm{E}\right)$. The trees were grafted on either 'JM1' or 'JM2' rootstocks (both Malus prunifolia). The effects of each 
rootstock on dormancy were not considered because our preliminary analysis indicated that their dormancy characteristics, such as bud burst dates, were almost the same (data not shown). The apple trees were grown using conventional cultural practices. In this study, we collected bud samples from the branches of trees grown under field conditions (2012-13 and 2014-15 seasons) or from excised branches exposed to an artificial chilling treatment. One-year-old middle branches (15$40 \mathrm{~cm}$ ) with terminal flower buds were collected and immediately transferred to our laboratory at Kyoto University (Kyoto, Japan) after being wrapped in moistened paper and maintained at $4-10{ }^{\circ} \mathrm{C}$. The basal parts of branches were then soaked in water containing $1 \%(\mathrm{v} / \mathrm{v})$ cut flower preservation reagent (Misakifarm; Otsuka Kagaku, Tokushima, Japan), which contains nutrients and fungicides that can extend the life of a cut flower. The water was changed every week, and the basal ends of the branches were cut. We examined the terminal flower buds rather than the lateral or leaf buds because flower buds are more closely associated with fruit production than leaf buds and the timing and depth of lateral bud dormancy may differ depending on bud position (Faust et al., 1995; Saure, 1985), which prevents accurate predictions of dormancy status. Flower buds were distinguished from vegetative buds based on the fact they are larger.

Calculation of The CU. The accumulated CU under field and chilling conditions was calculated on each sampling date according to the Utah model (Richardson et al., 1974). The ambient temperature (hourly mean temperature) in the field was obtained from the nearest weather station (Japan Meteorological Agency, Ina, Japan). The chilling treatment involved maintaining the temperature at $5^{\circ} \mathrm{C}\left(1 \mathrm{CU}=1 \mathrm{~h}\right.$ at $\left.5^{\circ} \mathrm{C}\right)$.

INVESTIGATION OF THE SEASONAL CHANGES OF DORMANCY STATUS IN THE FIELD. In the 2012-13 season, branches were collected on the following dates: 16 Oct., 20 Nov., and 19 Dec. 2012, and 16 Jan. and 12 Mar. 2013. The accumulated CU for each month was $0,434,810,994$, and 1295, respectively. During the 2014-15 season, branches were collected on 8 Nov. 2014 and 9 Jan. 2015, with an accumulated CU of 170 and 825 , respectively. The branches were artificially defoliated if they still contained leaves. They were then placed in growth chambers and incubated for 6 weeks at $22{ }^{\circ} \mathrm{C}$ under a $16 / 8-\mathrm{h}$ (light/dark) photoperiod. The terminal flower bud burst rates were then recorded for at least five branches (i.e., biological replications). The bud burst date was defined as the date when green leaf tips first became visible. Two or three terminal flower buds (i.e., biological replications) excised from the branches on each sampling date were used to construct RNA-Seq libraries. The excised flower buds were immediately frozen in liquid nitrogen and stored at $-80{ }^{\circ} \mathrm{C}$ until used.

INVESTIGATION OF THE DORMANCY STATUS OF BRANCHES UNDER CHILLING CONDITIONS. Branches were collected on 8 Nov. 2014 and artificially defoliated. They were subsequently incubated at $5^{\circ} \mathrm{C}$ in darkness for $0,10,20,30,40$, and $65 \mathrm{~d}$. The branches were then transferred to growth chambers set at $22{ }^{\circ} \mathrm{C}$ under a 16 -h light/ 8-h dark photoperiod. The accumulated CU for the $0,10,20,30$, 40 , and 65 d of chilling treatment was 170, 410, 650,890,1130, and 1730 , respectively. The terminal flower bud burst rates for four or five branches (i.e., biological replications) were recorded after 6 weeks in the growth chamber. Two or three branches (i.e., biological replications) that were chilled for $0,10,25,35$, and 65 $\mathrm{d}$ were used to construct RNA-Seq libraries. Terminal flower buds were collected and stored as described previously.
RNA EXTRACTION, LIBRARY CONSTRUCTION, AND RNA-SEQ. Total RNA was extracted from the field-grown tree samples collected during the 2012-13 season using CTAB as described by Yamane et al. (2008). The extracted total RNA was sent to BGI Japan (Kobe, Japan) for the construction of the mRNA library and the subsequent sequencing (HiSeq. 2000 system, PE100; Illumina, San Diego, CA). The raw reads were filtered to remove adapter sequences, contaminants, and low-quality reads, and the sequences were split based on the barcode information.

Total RNA was extracted from the field-grown tree samples collected during the 2014-15 season and from the samples exposed to the artificial chilling treatment with the Plant RNA Purification Reagent (Invitrogen, Carlsbad, CA) and then purified with a phenol/chloroform extraction. An mRNA library was constructed as described by Akagi et al. (2014), with minor modifications. Briefly, mRNA was isolated from total RNA using the Dynabeads mRNA purification kit (Thermo Fisher Scientific, Waltham, MA). First-strand cDNA was synthesized using SuperScript III reverse transcriptase (Invitrogen) and random primers. Second-strand cDNA was synthesized using the second-strand buffer (200 mM Tris- $\mathrm{HCl}$, $\mathrm{pH} 7.0,22 \mathrm{~mm} \mathrm{MgCl}_{2}$, and $425 \mathrm{~mm} \mathrm{KCl}$ ), DNA polymerase I (NEB, Ipswich, MA), and RNaseH (NEB). Double-stranded cDNA was purified using the Agencourt AMPure XP system (Beckman Coulter Genomics, Brea, CA), and then fragmented using NEBNext dsDNA Fragmentase (NEB). The fragmented DNA was subjected to end-repair, poly(A) tailing, adapter sequence ligation, size selection, and polymerase chain reaction enrichment. The resulting libraries were quantitatively and qualitatively assessed using the Agilent Bioanalyzer (Agilent Technologies, Santa Clara, CA) and Qubit fluorometer (Invitrogen). The libraries were then sequenced using the Illumina HiSeq 2000 system (PE100). After filtering, to remove lowquality reads and contaminants, the resulting clean reads were divided based on the barcode information, after which the adapter sequences were eliminated.

Calculation of the reads Per kilobase Per millions (RPKM). Clean reads were mapped to the apple consensus mRNA sequences (Daccord et al., 2017) using the BurrowsWheeler Aligner (Li and Durbin, 2009) with default parameters. The number of reads mapped to each gene was calculated using the Sequence Alignment/Map tool with custom R scripts. The raw read counts were normalized and converted to RPKM value.

Clustering and GO enrichment analysis. Before conducting the clustering analysis, the mean RPKM values of the biological replications were calculated for each condition, and genes with a low RPKM value or a low coefficient of variance (CV) score (mean RPKM $<1$ or $\mathrm{CV}<1$ for all conditions) were removed. The remaining genes were hierarchically clustered using the Morpheus software with one minus the Pearson correlation metric and the average-linkage method, based on a Z-score matrix calculated according to the mean RPKM value for each condition.

Published functional annotations of the GDDH13 v1.1 genome mapped with the InterProScan database (Daccord et al., 2017) were retrieved and used in this study. A GO enrichment analysis was conducted using the goseq package v1.22.0 (Young et al., $2010)$ with default parameters. A false discovery rate $($ FDR $)<0.1$ was used as the threshold for identifying significantly enriched GO terms, and GO terms with fewer than five genes in a given cluster were not employed in this study. 
SCREENING OF DEGS TO IDENTIFY GENES CLOSELY ASSOCIATED WITH ENDODORMANCY RELEASE AND THE FULFILLMENT OF THE CR. We assumed that genes encoding putative master regulators of endodormancy release were differentially expressed between endo- and ecodormant buds. We also assumed that changes to the expression levels of endodormancy- and CRrelated genes are associated with chilling accumulation because the shift from endo-to ecodormancy is theoretically correlated with chilling accumulation (Lang, 1987). The genes differentially expressed between endo- and ecodormant flower buds were analyzed using the DESeq R package (Anders and Huber, 2010). The FDR (Benjamini and Hochberg, 1995) and a threshold of 0.05 was used to identify DEGs. In addition, the Pearson correlation ( $r$ ) between the gene expression value (RPKM) and the CU was calculated using Excel (Microsoft, Redmond, WA). Genes whose expression was statistically correlated with the CU $(|r|>0.6)$ were identified. The outline of our strategy is presented in Fig. 1. Genes selected according to our hypothesis were annotated based on a BLAST search of the nonredundant NCBI database. The genes with the highest matches were identified.

Phylogenetic analysis of the apple FlC-like gene. A putative MADS-box-like gene was included among the screened genes. The FLC clade MADS-box genes were retrieved from genome sequences of apple, arabidopsis, peach, grape (Vitis vinifera), and poplar (Populus trichocarpa) using FLC from arabidopsis (Pařenicová et al., 2003) as query by BLAST search. Then, phylogenetic tree was constructed using the amino acid sequences of these retrieved genes and arabidopsis MADS-box genes (Pařenicová et al., 2003) according to the neighbor-joining method with 1000 bootstrap replications. The trees were prepared using the MEGA7 program (Kumar et al., 2016b), and were based on a sequence alignment using MAFFT version 7.0 (Katoh and Standley, 2013) and arrangement with trimAL (Capella-Gutiérrez et al., 2009).

\section{Results}

DORMANCY STATUS OF BRANCHES UNDER CHILLING CONDITIONS. The results of our field analysis were consistent with the observations of a previous study, which revealed that 'Fuji' apple trees require about $1000 \mathrm{CU}$ for endodormancy release (Hauagge and Cummins, 1991). Samples, Jan. 2013, Mar. 2013, and Jan. 2015 accumulated $\approx 1000 \mathrm{CU}$ and had bud burst rates of $100 \%$ (Table 1; Fig. 2A and B). By contrast, under artificial chilling conditions, the highest bud burst rate was $60 \%$ after $40 \mathrm{~d}$, even though the samples accumulated about $1000 \mathrm{CU}$ (Fig. 2C). To identify the genes differentially expressed between the endodormancy and ecodormancy stages, samples were classified as endodormant, ecodormant, or in transition (i.e., from endodormancy to ecodormancy) based on the recorded bud burst rate under forcing conditions. Bud burst rates of $0 \%$ and $100 \%$ were defined as endo- and ecodormancy, respectively. For the RNA-Seq analysis, four sampling time points [Oct. 2012, Nov. 2012, Nov. 2014 (0 d), and $10 \mathrm{~d}$ ] represented endodormancy, whereas three sampling time points (Jan. 2013, Mar. 2013, and Jan. 2015) corresponded to ecodormancy.

RNA-SEQ, MAPPING TO A NEW APPLE REFERENCE GENOME, AND CLUSTER ANALYSIS. Eleven samples were analyzed, with each consisting of two or three biological replications. About 0.5 billion clean reads (100 nucleotides long) were obtained, with each sample comprising 27-68 million reads (Table 1). With the exception of one sample with an extremely low mapping rate $(28.2 \%$ for $0 \mathrm{~d}-\mathrm{C})$, the average mapping rate was $78.2 \%$, reflecting sequence differences between the 'GDDH13' (used to construct the reference genome) and 'Fuji' (used in this study) genomes (data not shown). The data for $0 \mathrm{~d}-\mathrm{C}$ were excluded from subsequent analyses. All the obtained sequences from Illumina sequencing reads are available from the NCBI/ DDBJ Sequence Read Archive under the following accession numbers, DRA006592 (PRJDB6779).

A cluster analysis divided the expressed genes into eight clusters based on the global expression patterns (Fig. 3). The genes in cluster 1 were highly expressed at 10 and $25 \mathrm{~d}$ after chilling but their expression levels were downregulated at 35 and $65 \mathrm{~d}$. By contrast, the expression levels of the cluster 2 genes were upregulated in response to a continuous chilling condition. The cluster 1 and 2 genes did not exhibit differential expression under a natural chilling condition. However, the expression levels of the genes in clusters 3-8 did not significantly change under a continuous chilling condition but underwent global changes under a natural chilling condition. The expression levels of genes in clusters 3 and 8 were considerably upregulated in samples collected in Jan. 2015 and 2013, respectively. Meanwhile, cluster 4 gene expression levels were up-regulated in Mar. 2013, whereas the expression levels of genes in clusters 5 and 6 were up-regulated in Nov. 2014 and 2012 , respectively. The expression levels of genes in clusters 4 6 were generally down-regulated in samples collected in December and January. By contrast, the cluster 7 gene expression levels were upregulated in October and December but downregulated from January onward.

The enriched GO terms in each cluster are listed in Table 2. No GO terms were significantly enriched in clusters 3, 5, 6, and 8 . However, in cluster 4, GO terms related to cell division, such as "DNA replication" and "regulation of cell cycle," were

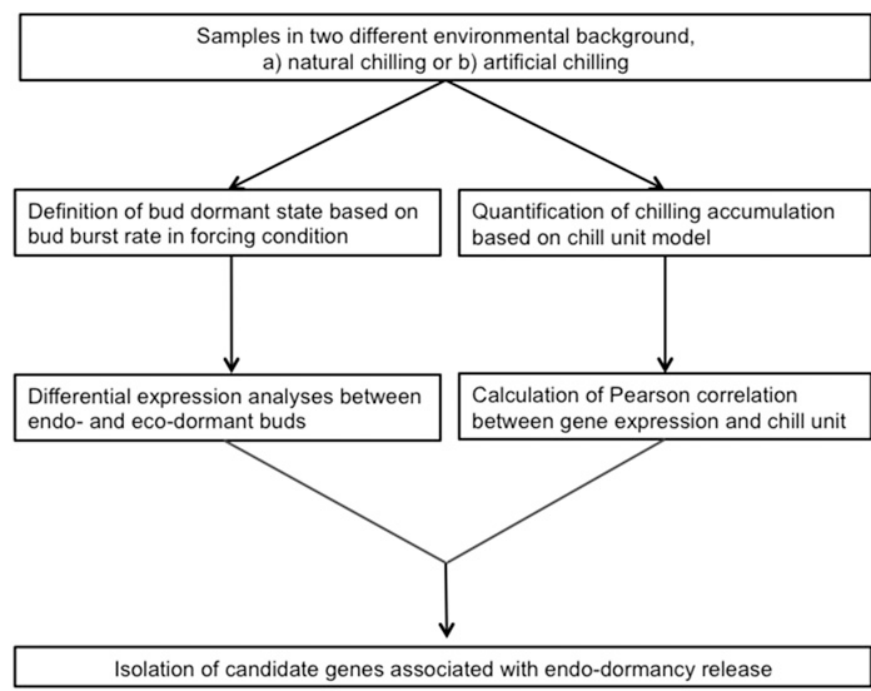

Fig. 1. Outline of the strategy used to identify potential regulators of apple endodormancy release. Samples were treated with natural or artificial chilling conditions. Candidate genes were narrowed down according to the following criteria: 1) the gene should be differentially expressed in the buds between endodormancy ( $0 \%$ budbreak under forcing conditions) and ecodormancy $(100 \%$ budbreak under forcing conditions) and 2) the expression of the gene should be correlated with the chilling accumulation required for endodormancy release. 
enriched, suggesting that active bud outgrowth started in March. The GO terms related to oxidative stress were enriched in clusters 2 and 7, which consisted of genes whose expression levels were up-regulated in response to a prolonged cold treatment under continuous and natural chilling conditions, respectively. This suggested that responses to oxidative stress, including enhanced peroxidase activity, may contribute to the physiological changes induced by a prolonged exposure to low temperatures, such as dormancy release, cold adaptation and hardening or both.

Screening of DEGs. Our analyses with 12 pairwise comparisons (FDR $<0.05)$, using four endo- and three ecodormancy samples revealed that 184 genes were differentially expressed in common in all comparisons (data not shown), even though 4039-20,488 DEGs were identified in each comparison (Table 3). The Pearson correlation $(r)$ between the RPKM value and the $\mathrm{CU}$ was calculated for $\approx 44,953$ mapped genes in the apple genome. We detected $\approx 5522$ genes whose expression was highly correlated with the CU $(|r|>0.6)$. More than $95 \%$ of the correlations were positive, with negative correlations observed for only 237 genes. Of the 184 genes that were differentially expressed, the expression levels of 13 and 31 were positively and negatively correlated with the CU, respectively (Table 4). These genes were annotated based on
A.

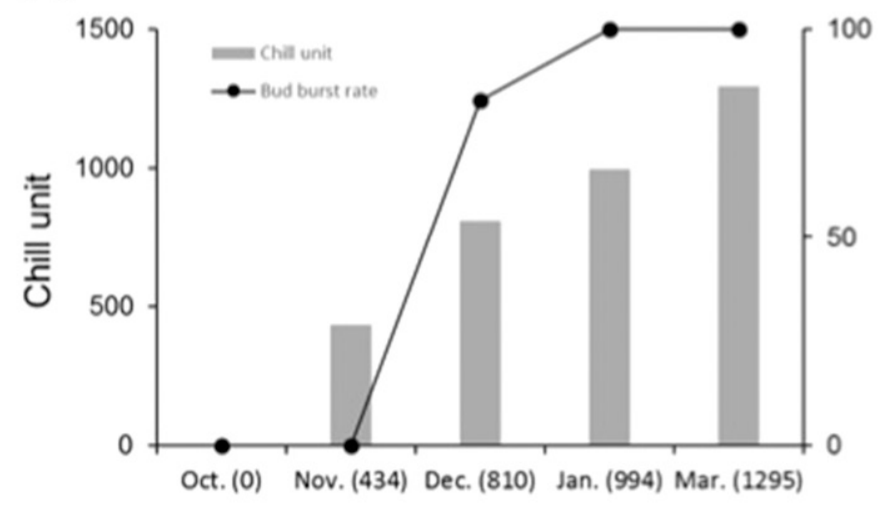

C.

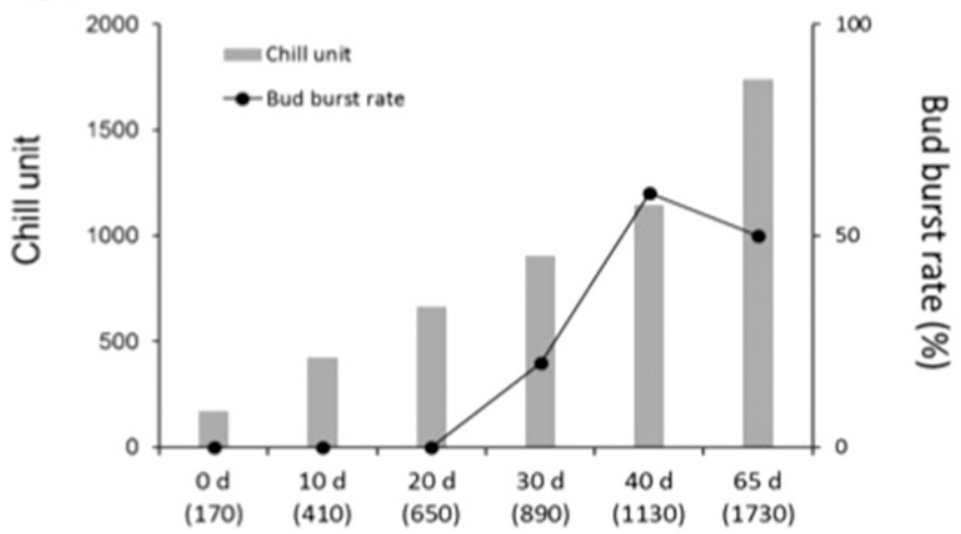

B.

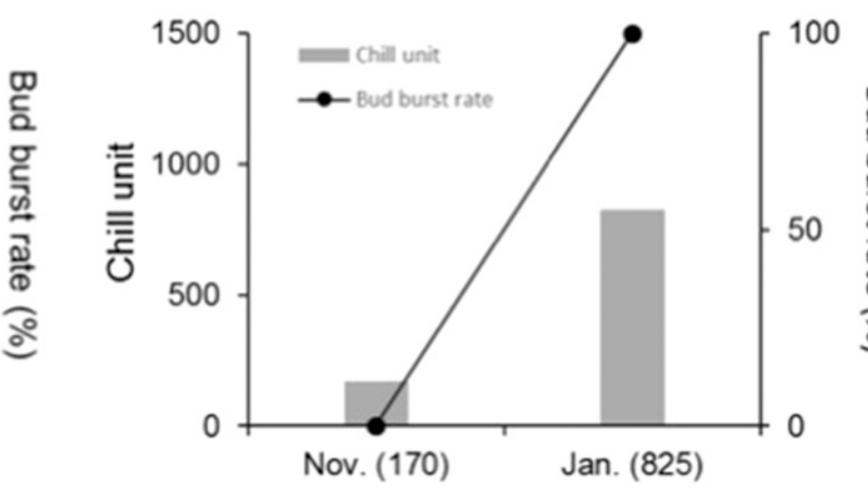

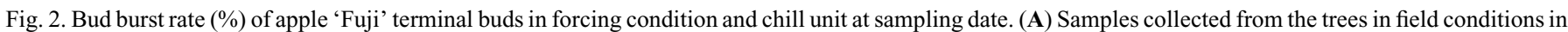
2012-13, (B) samples collected from the trees in field conditions in 2014-15, and (C) samples collected from the branches exposed to artificial chilling conditions. Chill units were shown in parentheses of each sample name. 


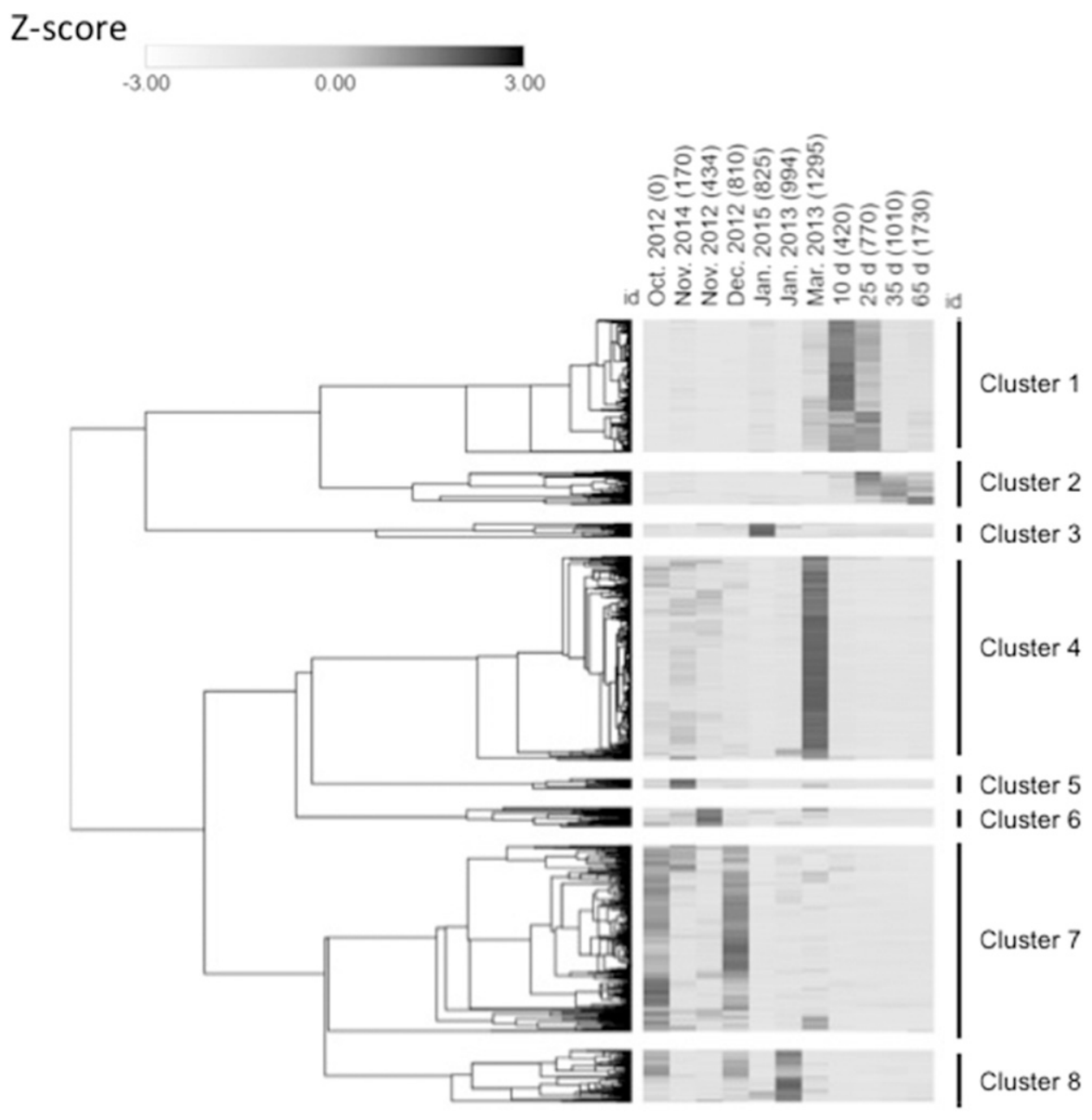

Fig. 3. Hierarchical clustering of the expressed genes in apple dormant buds. Chill units were shown in parentheses of each sample name. Eight clusters were constructed.

a BLAST search and five genes encoded transcription factors. The annotations indicated that MD09G1146000, MD09G1009100, MD14G1126900, MD16G1140800, and MD15G1369700 encode PHYTOCHROME-INTERACTING FACTOR 4 (PIF4), MADS-BOX-LIKE, MYC2-LIKE, APETALLA2/ETHYLENERESPONSIVE 113 (ERF113), and ODORANT1 (ODO1) transcription factors, respectively. First four genes and the last one exhibited considerably up-regulated and down-regulated expression, respectively, in response to the chilling treatment (Fig. 4). Among five transcription factor genes, MADS-BOX-LIKE and $O D O 1$ fell into cluster 2 and cluster 7, respectively, suggesting that expression changes of these genes may be related to oxidative stress. Other three genes were not included in cluster analysis (data not shown). As for $M A D S-B O X-L I K E$, our phylogenetic tree constructed using MD09G1009100 and FLC clade genes in arabidopsis, grape, peach, and poplar indicated that MD09G1009100 encodes a MADS-box transcription factor belonging to the FLC clade (Fig. 5), even though it was annotated as a truncated CAULIFLOWER D-like transcription factor in the apple genome database. The results of a BLAST search suggested this gene was highly similar to the japanese pear FLC-like gene sequence (accession no. AB524589; e $=1 \times$ $10^{-23}$ ). Most $D A M$ genes including $M d D A M 1-4$ were not included in our DEG list and also in GO analysis because of either lower RPKM value or a lower CV score.

\section{Discussion}

Characterization OF THE DORMANCY STATUS AND GENE EXPRESSION LEVELS IN TERMINAL FLOWER BUDS UNDER DIFFERENT ENVIRONMENTAL CONDITIONS. Quantitatively analyzing the state of bud dormancy is very challenging, and there are still few molecular and physiological markers suitable for evaluating the bud endodormancy state. The bud burst rate under forcing conditions has traditionally been used to predict the endodormancy status. In addition, the accumulated $\mathrm{CU}$ is useful for evaluating endodormancy progression. Thus, we analyzed the bud burst rate and the CU at several time points during the endodormancy period in the field and under artificial chilling conditions (Fig. 2). As expected, the bud burst rate gradually increased with increasing CU. However, the bud burst rate decreased in response to a chilling treatment and did not reach 100\% even after a normally sufficient exposure to chilling conditions. We suspected that some stresses associated with the prolonged chilling of detached branches contributed to the decrease in bud burst rate. It is possible that the buds exposed to continuous chilling stress may require more extensive chilling for dormancy release compared with buds exposed to chilling conditions in the field. If this is the case, the exact CR may vary considerably depending on environmental conditions. Further studies will be required to test this hypothesis.

Our cluster analysis revealed that the genes differentially expressed under natural chilling conditions did not exhibit global expression-level changes in response to continuous chilling, and vice versa (Fig. 3). This suggested that the global expression patterns differed between the field-grown naturally chilled buds and the continuously chilled buds, even though they were exposed to similar amounts of accumulated chilling and expected to have a similar dormancy status. Comparing samples from more than one environmental background can easily lead to the exclusion of genes affected by specific environmental changes. This results in the detection of genes related to a specific endogenous status (e.g., dormancy status) but whose expression-level changes are unaffected by specific environmental conditions. Nevertheless, some GO terms, such as "oxidation-reduction process" and "iron ion binding," were enriched in clusters 2 and 7 (Table 2), which comprised genes whose expression levels were up-regulated during prolonged chilling under continuous and natural chilling conditions, respectively. This result is consistent with the previous finding that oxidative stress and oxidation-reduction pathways are associated with prolonged chilling-induced physiological 
Table 2. Significantly enriched gene ontology (GO) terms in clusters 1, 2, 4, and 7 constructed by cluster analysis (Fig. 3) of apple dormant buds RNA-Seq reads.

\begin{tabular}{|c|c|c|c|c|c|c|}
\hline Cluster & GO ID & numDEInCat $^{z}$ & numInCat $^{y}$ & GO term & Ontology $^{x}$ & $\mathrm{FDR}^{\mathrm{w}}$ \\
\hline \multicolumn{7}{|l|}{$\begin{array}{ll}\mathrm{cl} .1 \\
\end{array}$} \\
\hline & GO:0015074 & 8 & 78 & DNA integration & $\mathrm{BP}$ & 0 \\
\hline & GO:0003676 & 20 & 1177 & Nucleic acid binding & MF & $1.31 \mathrm{E}-11$ \\
\hline \multicolumn{7}{|l|}{$\mathrm{cl} .2$} \\
\hline & GO:0008171 & 6 & 73 & O-methyltransferase activity & MF & $1.34 \mathrm{E}-04$ \\
\hline & GO:0009058 & 8 & 242 & Biosynthetic process & $\mathrm{BP}$ & $1.34 \mathrm{E}-04$ \\
\hline & GO:0020037 & 11 & 657 & Heme binding & MF & $1.71 \mathrm{E}-03$ \\
\hline & GO:0008152 & 15 & 1375 & Metabolic process & $\mathrm{BP}$ & $1.71 \mathrm{E}-03$ \\
\hline & GO:0009055 & 11 & 747 & Electron carrier activity & MF & 4.54E-03 \\
\hline & GO:0055114 & 18 & 2123 & Oxidation-reduction process & BP & $5.17 \mathrm{E}-03$ \\
\hline & GO:0005506 & 9 & 639 & Iron ion binding & MF & $1.76 \mathrm{E}-02$ \\
\hline & GO:0003824 & 14 & 1885 & Catalytic activity & MF & $6.07 \mathrm{E}-02$ \\
\hline \multicolumn{7}{|l|}{$\mathrm{cl} .4$} \\
\hline & GO:0006334 & 23 & 106 & Nucleosome assembly & BP & $6.29 \mathrm{E}-22$ \\
\hline & GO:0000786 & 22 & 101 & Nucleosome & $\mathrm{CC}$ & $2.11 \mathrm{E}-21$ \\
\hline & GO:0046982 & 22 & 134 & Protein heterodimerization activity & MF & $1.23 \mathrm{E}-18$ \\
\hline & GO:0006270 & 11 & 19 & DNA replication initiation & $\mathrm{BP}$ & 4.07E-14 \\
\hline & GO:0005634 & 49 & 1016 & Nucleus & $\mathrm{CC}$ & $4.81 \mathrm{E}-14$ \\
\hline & GO:0008017 & 20 & 128 & Microtubule binding & MF & $1.62 \mathrm{E}-13$ \\
\hline & GO:0006260 & 18 & 100 & DNA replication & $\mathrm{BP}$ & $1.62 \mathrm{E}-13$ \\
\hline & GO:0042555 & 10 & 17 & MCM complex & $\mathrm{CC}$ & $4.04 \mathrm{E}-13$ \\
\hline & GO:0005871 & 18 & 110 & Kinesin complex & $\mathrm{CC}$ & $1.37 \mathrm{E}-12$ \\
\hline & GO:0003777 & 18 & 111 & Microtubule motor activity & MF & $1.37 \mathrm{E}-12$ \\
\hline & GO:0007018 & 18 & 111 & Microtubule-based movement & $\mathrm{BP}$ & $1.37 \mathrm{E}-12$ \\
\hline & GO:0003678 & 10 & 22 & DNA helicase activity & MF & $6.17 \mathrm{E}-12$ \\
\hline & GO:0003677 & 62 & 1973 & DNA binding & MF & $6.71 \mathrm{E}-11$ \\
\hline & GO:0051726 & 10 & 29 & Regulation of cell cycle & $\mathrm{BP}$ & $2.49 \mathrm{E}-10$ \\
\hline & GO:0000079 & 10 & 48 & Regulation of cyclin-dependent protein serine/threonine kinase activity & $\mathrm{BP}$ & 3.49E-08 \\
\hline & GO:0019901 & 10 & 48 & Protein kinase binding & MF & 3.49E-08 \\
\hline & GO:0005576 & 11 & 80 & Extracellular region & $\mathrm{CC}$ & 4.98E-08 \\
\hline & GO:0009664 & 8 & 44 & Plant-type cell wall organization & $\mathrm{BP}$ & $1.46 \mathrm{E}-06$ \\
\hline & GO:0005874 & 7 & 41 & Microtubule & $\mathrm{CC}$ & $5.43 \mathrm{E}-05$ \\
\hline & GO:0005200 & 5 & 36 & Structural constituent of cytoskeleton & MF & 4.48E-03 \\
\hline & GO:0043234 & 5 & 33 & Protein complex & $\mathrm{CC}$ & 4.48E-03 \\
\hline & GO:0051258 & 5 & 33 & Protein polymerization & $\mathrm{BP}$ & 4.48E-03 \\
\hline & GO:0007017 & 5 & 48 & Microtubule-based process & $\mathrm{BP}$ & $1.63 \mathrm{E}-02$ \\
\hline & GO:0005524 & 68 & 3470 & ATP binding & MF & $1.76 \mathrm{E}-02$ \\
\hline & GO:0015979 & 6 & 91 & Photosynthesis & $\mathrm{BP}$ & $1.85 \mathrm{E}-02$ \\
\hline & GO:0005975 & 19 & 739 & Carbohydrate metabolic process & BP & $8.90 \mathrm{E}-02$ \\
\hline \multicolumn{7}{|c|}{ 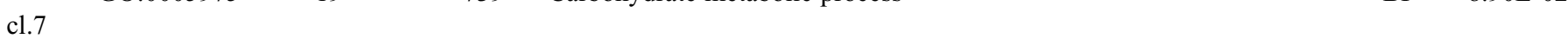 } \\
\hline & GO:0048046 & 12 & 80 & Apoplast & $\mathrm{CC}$ & $1.13 \mathrm{E}-07$ \\
\hline & GO:0046274 & 8 & 47 & Lignin catabolic process & $\mathrm{BP}$ & 7.58E-06 \\
\hline & GO:0052716 & 8 & 47 & Hydroquinone:oxygen oxidoreductase activity & MF & $7.58 \mathrm{E}-06$ \\
\hline & GO:0055114 & 52 & 2123 & Oxidation-reduction process & $\mathrm{BP}$ & 4.24E-05 \\
\hline & GO:0016165 & 5 & 26 & Linoleate 13 S-lipoxygenase activity & MF & $6.03 \mathrm{E}-05$ \\
\hline & GO:0046872 & 24 & 767 & Metal ion binding & MF & 8.77E-05 \\
\hline & GO:0005507 & 14 & 222 & Copper ion binding & MF & $1.11 \mathrm{E}-04$ \\
\hline & GO:0006629 & 16 & 330 & Lipid metabolic process & $\mathrm{BP}$ & 2.98E-04 \\
\hline & GO:0020037 & 24 & 657 & Heme binding & MF & 3.75E-04 \\
\hline & GO:0004601 & 11 & 162 & Peroxidase activity & MF & $1.39 \mathrm{E}-03$ \\
\hline & GO:0006979 & 11 & 171 & Response to oxidative stress & BP & 2.79E-03 \\
\hline & GO:0005506 & 20 & 639 & Iron ion binding & MF & $6.94 \mathrm{E}-03$ \\
\hline & GO:0016787 & 18 & 578 & Hydrolase activity & MF & 2.37E-02 \\
\hline & GO:0003700 & 21 & 765 & Transcription factor activity, sequence-specific DNA binding & MF & 2.61E-02 \\
\hline & GO:0005509 & 13 & 406 & Calcium ion binding & MF & $6.50 \mathrm{E}-02$ \\
\hline
\end{tabular}

${ }^{\mathrm{z}}$ Number of differentially expressed genes included in this ontology.

${ }^{\mathrm{y}}$ Number of total genes included in this ontology.

${ }^{\mathrm{x}} \mathrm{BP}=$ biological process; $\mathrm{MF}=$ molecular function; $\mathrm{CC}=$ cellular component.

${ }^{\mathrm{w}}$ False discovery rate. 
Table 3. Number of differentially expressed genes (false discovery rate $<0.05)$ between endo- and ecodormant apple flower bud samples. Twelve pairwise comparisons were performed using four endo- and three ecodormant samples assigned based on bud burst rate in forcing condition (Fig. 2).

\begin{tabular}{llrrr}
\hline & & \multicolumn{3}{c}{ Ecodormancy } \\
\cline { 3 - 5 } & & Jan. 2013 & Mar. 2013 & Jan. 2015 \\
\hline Endodormancy & Oct. 2012 & 5,406 & 7,728 & 6,151 \\
& Nov. 2012 & 16,698 & 10,313 & 8,176 \\
& Nov. 2014 $(0$ d) & 12,448 & 4,039 & 5,936 \\
& 10 d & 20,488 & 8,906 & 4,802 \\
\hline
\end{tabular}

changes, such as dormancy release (Bai et al., 2013, Khalil-UrRehman et al., 2017, Liu et al., 2012), cold hardening or both (John et al., 2016).

IDENTIFICATION OF TRANSCRIPTION FACTOR GENES ASSOCIATED WITH ENDODORMANCY RELEASE IN APPLE. Transcription factors have significant roles as master regulators of diverse plant traits (Becker and Theissen, 2003; Ng and Yanofsky, 2001). The aim of this study was to identify candidate master regulators of dormancy release and the $\mathrm{CR}$, and transcription factors may be suitable for this role. Although most of the identified genes in DEG list encoded enzymes involved in metabolic processes,

Table 4. Gene annotations and Pearson correlation $(r)$ between the gene expression value reads per kilobase of millions and the chill unit for the 44 genes differentially expressed between endo- and ecodormancy in terminal flower buds. Genes were annotated based on a BLAST search of the NCBI non-redundant (nr) database. The top matches are listed.

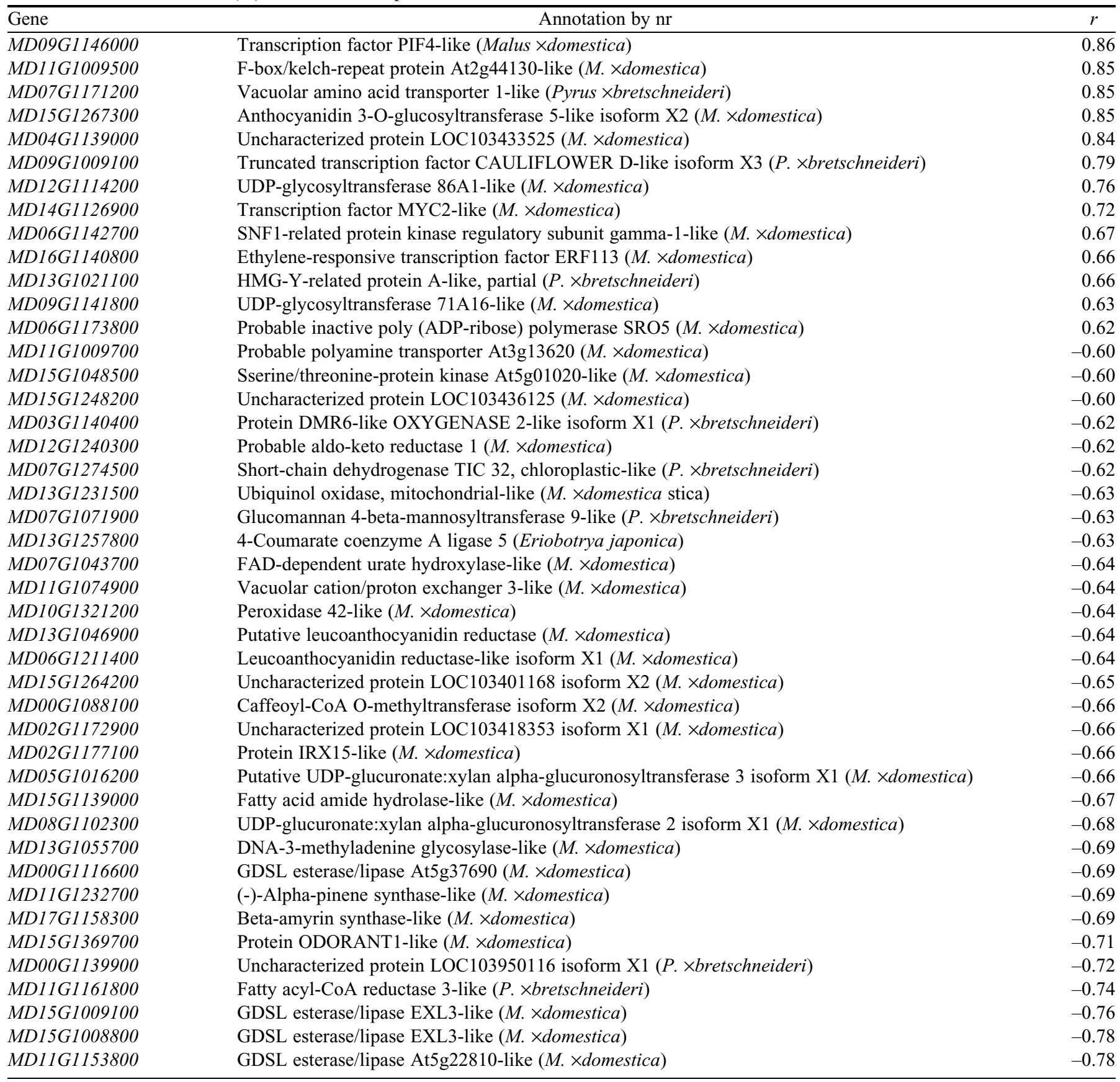

PIF4 = phytochrome-interacting factor 4. 

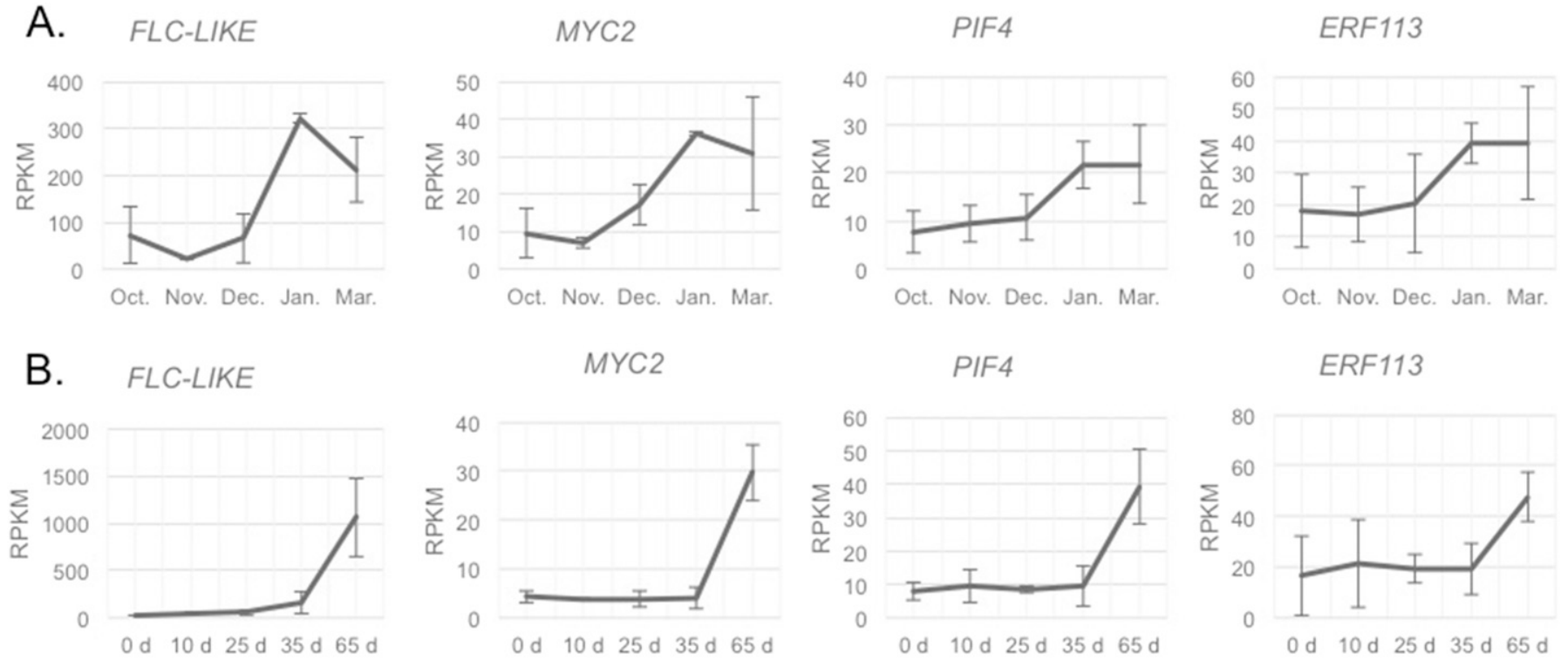
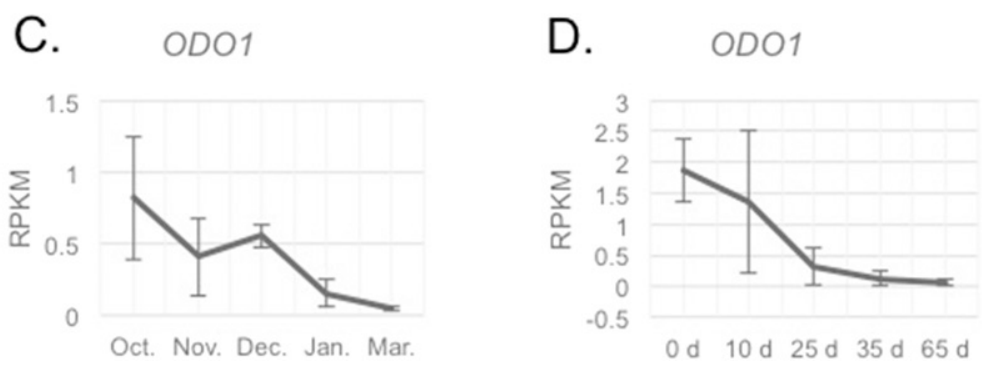

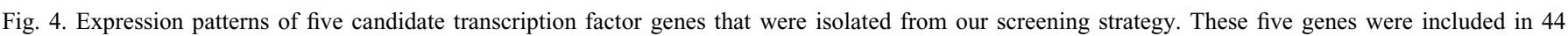
differentially expressed genes (DEGs) differentially expressed between endodormancy and ecodormancy, with showing expression changes correlated with chill units. Expression patterns in field conditions in 2012-13 (A, C) and artificial chilling conditions (B, D). (A, B) Four DEGs up-regulated during dormancy release. (C, D) One DEG down-regulated during dormancy release. FLOWERING LOCUS C-LIKE (FLC-LIKE): MD09G1009100, MYC2: MD14G1126900, PHYTOCHROME-INTERACTING FACTOR 4 (PIF4): MD09G1146000, APETALLA2/ETHYLENE-RESPONSIVE113 (AP2/ERF113): MD16G1140800, ODORANT1 (ODO1): MD15G1369700. Error bars represent SD.

such as GDSL esterase/lipase, hydrolase and transporters (Table 3), five genes, PIF4, MYC2, FLC-LIKE, AP2/ERF113, and $O D O 1$, encoded transcription factors. Among them, PIF4 and $M Y C 2$ were known to be related to phytohormone metabolism, whereas $A P 2 / E R F 113$ was involved in meristem activity. PIF4 regulates auxin biosynthesis at high temperature (Franklin et al., 2011) and positively regulates growth and development at elevated temperature (Gangappa et al., 2017). $M Y C 2$ is a master regulator of the response to the jasmonate in arabidopsis and is involved in jasmonic acid-regulated plant development, lateral adventitious root formation, flowering time, and shade avoidance syndrome (Goossens et al., 2015; Kazan and Manners, 2013). AP2/ERF113 promotes shoot regeneration from calli (Che et al., 2006) and related to tissue repair in floral stem (Asahina et al., 2011). On the other hand, $O D O 1$ encodes R2R3-MYB transcription factor and regulates volatile benzenoid/phenylpropanoid biosynthesis pathway in petunia [Petunia Xhybrida (Colquhoun and Clark, 2011)], suggesting that it might be involved in secondary metabolism than dormancy regulation. In fact, an anthocyanin biosynthesisrelated gene, leucoanthocyanidin reductase gene, was also included in DEG list as with ODO1. To the best of our knowledge, none of the reports focused on PIF4, MYC2, and $A P 2 / E R F 113$, regarding bud dormancy regulation so far, and our findings suggested that auxin biosynthesis, jasmonic acid signaling, and meristem activity that are mediated by PIF4, $M Y C 2$, and $A P 2 / E R F 113$, respectively, are associated with dormancy release in apple. Our identification of transcription factors involved in phytohormone metabolism and meristem activity is consistent with the previous report suggesting that phytohormone-related pathways and post-embryonic development may be involved in chilling-mediated dormancy release and fruit set in apple (Kumar et al., 2017).

As for FLC-LIKE, our results are consistent with the previous finding that an FLC-LIKE gene is differentially expressed during apple dormancy release (Porto et al., 2015). Md09G1009100 was localized to the upper distal part of chromosome nine, which was recently indicated as being involved in the genetic control of flowering or vegetative budbreak (Allard et al., 2016; Celton et al., 2011; Urrestarazu et al., 2017; van Dyk et al., 2010). Significant FLC and FLC$L I K E$ gene expression changes during dormancy were also reported for chinese cherry [Prunus pseudocerasus (Zhu et al., 2015)], leafy spurge (Doğramaci et al., 2014), Taihangia rupestris (Du et al., 2008), and trifoliate orange [Poncirus trifoliata (Zhang et al., 2009)]. Kumar et al. (2016a) revealed that the expression levels of certain FLC-LIKE genes (MDP0000186558 and MDP0000218227) are down-regulated 
toward the end of the dormancy and budbreak stage. They also completed a genome-wide phylogenetic analysis of the apple MADS-box gene family and identified four putative FLC-LIKE

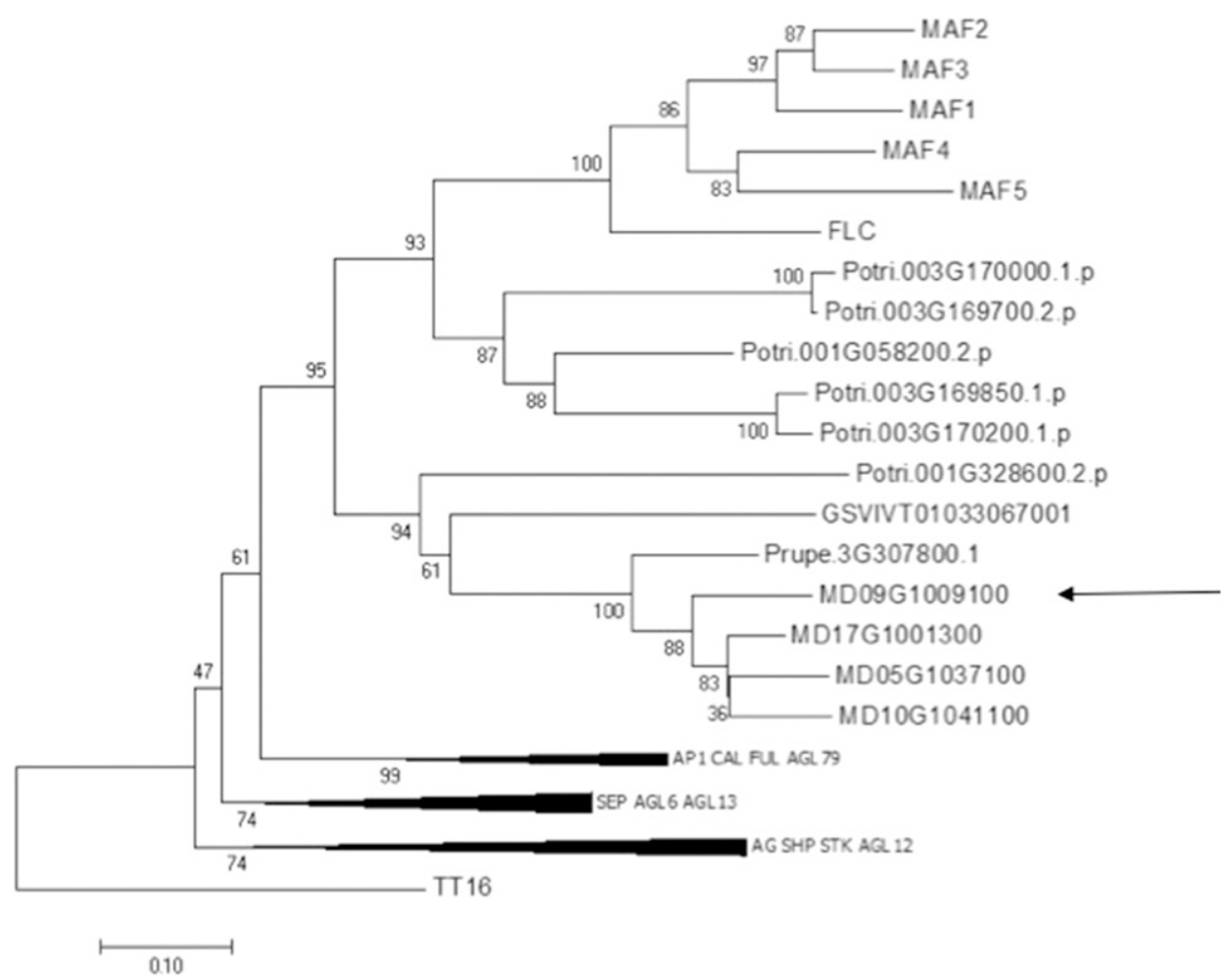

Fig. 5. Phylogenetic tree consisting of FLOWERING LOCUS C (FLC) clade genes from arabidopsis (FLC, MAF1-5), grape (GSVIVT01033067001), peach (Prupe.3G307800.1), poplar (Potri001G328600, 001G058200, 003G169700, 003G169850, 003G170000, 003G170200), and apple (MD05G1037100, 09G1009100, 10G1041100, 17G1001300) and some MADS-box genes from arabidopsis. The tree was constructed with 1000 bootstrap replication using the MEGA7 program (Kumar et al., 2016b), followed by an amino acid sequence alignment using MAFFT (Katoh and Standley, 2013) and trimAL (Capella-Gutiérrez et al., 2009). The arrow indicates the position of MD09G1009100. genes. MD09G1009100 (MDP0000126259 and MDP0000167381 in the old version of the apple genome) was not included among the four genes probably because of a lack of a MADSdomain in MDP0000126259 and MDP0000167381. Although we revealed the up-regulation of MD09G1009100 expression during endodormancy release, we cannot rule out the possibility that it is down-regulated toward the end of the dormancy and budbreak stage as is the case for other FLC-LIKE genes (Kumar et al., 2016a). Indeed, MD09G1009100 was down-regulated from January to March, specifically during the transition from the ecodormancy stage to the budbreak stage. So far, there have been inconsistencies regarding the presence and identification of apple FLC-LIKE genes in previous studies by different researchers, for example, Tian et al. (2015) did not detect any FLC-LIKE genes when they examined the apple MADS-box gene family. Thus, we identified apple FLC-LIKE genes using a recently updated version of the apple genome. A BLAST search of the apple genome using the MD09G1009100 amino acid sequence as a query identified six genes with high e values $\left(\mathrm{e}<1 \times 10^{-2}\right)$. A phylogenetic analysis revealed that four of these genes belong to the $F L C$ clade and two genes were included in the clade other than

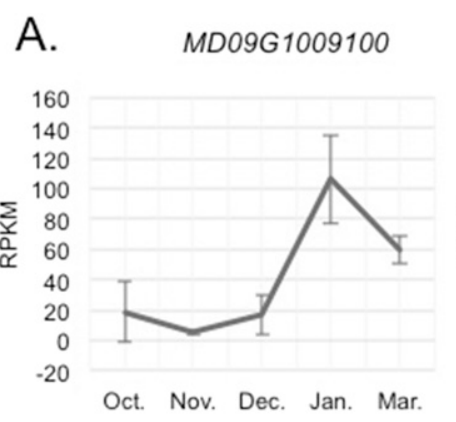

B.

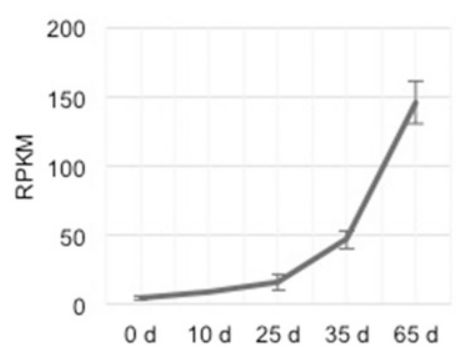

MD17G1001300

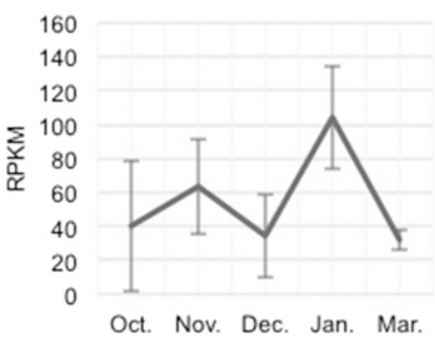

MD17G1001300

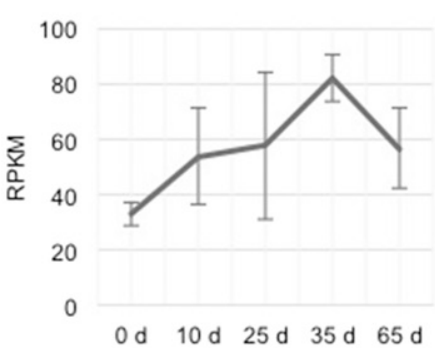

MD05G1037100

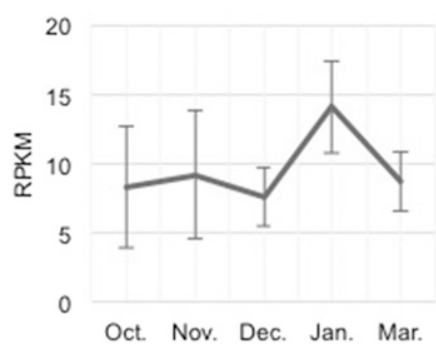

MD05G1037100

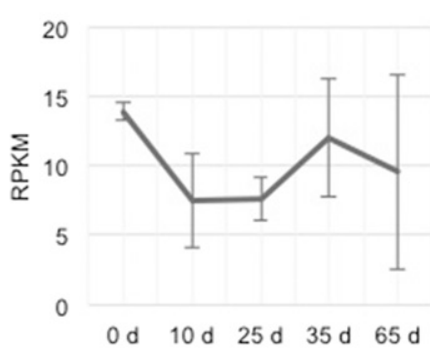

MD10G1041100

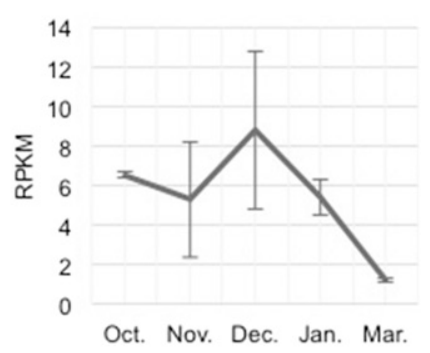

MD10G1041100

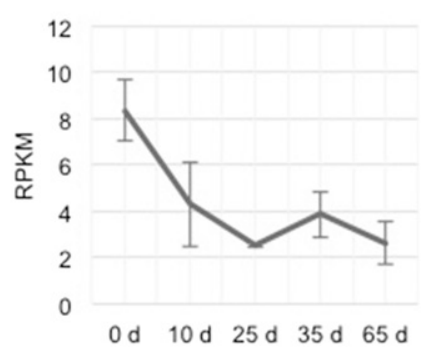

Fig. 6. Expression patterns of apple FLOWERING LOCUS C-LIKE (FLC-LIKE) gene, MD09G1009100, and three other FLC-LIKE genes, MD05G1037100, $M D 10 G 1041100$, and MD17G1001300, under field conditions in 2012-13 (A) and under chilling treatment conditions (B). Error bars represent SD. 
FLC (data not shown). As consequence, we identified four FLC-LIKE genes (MD05G1037100, MD09G1009100, $M D 10 G 1041100$, and $M D 17 G 1001300)$ in apple genome. None of these genes correspond to the FLC-LIKE genes identified by Kumar et al. (2016a). The expression patterns of three identified FLC-LIKE genes, which differed from that of $M D 09 G 1009100$, did not exhibit dormancy-related expression changes, suggesting these genes are likely unrelated to endodormancy release (Fig. 6). Additional studies focusing on the biological function of $M D 09 G 1009100$ will help to clarify its role during endodormancy and budbreak. In addition, because poor performance of budbreak often occurs in lateral vegetative buds than in terminal flower buds, the involvement of MD09G1009100 on bud dormancy regulation in lateral parts should be focused in the future to solve the problem about budbreak disorder caused by global climate change.

In conclusion, our RNA-Seq analysis identified four transcription factor genes, PIF4, FLC-LIKE, AP2/ERF113, and $M Y C 2$, that were correlated with the $\mathrm{CU}$ and expressed differently between endodormant and ecodormant buds, suggesting that these transcription factors are closely associated with chilling-mediated endodormancy release in apple.

\section{Literature Cited}

Akagi, T., I. Henry, R. Tao, and L. Comai. 2014. Plant genetics. A Y-chromosome-encoded small RNA acts as a sex determinant in persimmons. Science 346:646-650.

Allard, A., M.C.A.M. Bink, S. Martinez, J-J. Kelner, J-M. Legave, M. di Guardo, E.A. Di Pierro, F. Laurens, E.W. van de Weg, and E. Constes. 2016. Detecting QTLs and putative candidate genes involved in budbreak and flowering time in an apple multiparental population. J. Expt. Bot. 67:2875-2888.

Anders, S. and W. Huber. 2010. Differential expression analysis for sequence count data. Genome Biol. 11:R106.

Asahina, M., K. Azuma, W. Pitaksaringkarn, T. Yamazaki, N. Mitsuda, M. Ohme-Takagi, S. Yamaguchi, Y. Kamiya, K. Okada, T. Nishimura, T. Koshiba, T. Yokota, H. Kamada, and S. Satoh. 2011. Spatially selective hormonal control of RAP2. 6L and ANAC071 transcription factors involved in tissue reunion in arabidopsis. Proc. Natl. Acad. Sci. USA 108:16128-16132.

Bai, S., T. Saito, D. Sakamoto, A. Ito, H. Fujii, and T. Moriguchi. 2013. Transcriptome analysis of Japanese pear (Pyrus pyrifolia Nakai) flower buds transitioning through endodormancy. Plant Cell Physiol. 54:1132-1151.

Becker, A. and G. Theissen. 2003. The major clades of MADS-box genes and their role in the development and evolution of flowering plants. Mol. Phylogenet. Evol. 29:464-489.

Benjamini, Y. and Y. Hochberg. 1995. Controlling the false discovery rate: A practical and powerful approach to multiple testing. J. R. Stat. Soc. B 57:289-300.

Bielenberg, D., Y. Wang, Z. Li, T. Zhebentyayeva, S. Fan, G. Reighard, R. Scorza, and A. Abbott. 2008. Sequencing and annotation of the evergrowing locus in peach [Prunus persica (L.) Batsch] reveals a cluster of six MADS-box transcription factors as candidate genes for regulation of terminal bud formation. Tree Genet. Genomes 4:495-507.

Böhlenius, H., T. Huang, L. Charbonnel-Campaa, A. Brunner, S. Jansson, S. Strauss, and O. Nilsson. 2006. CO/FT regulatory module controls timing of flowering and seasonal growth cessation in trees. Science 312:1040-1043.

Capella-Gutiérrez, S., J.M. Silla-Martínez, and T. Gabaldón. 2009. TrimAl: A tool for automated alignment trimming in large-scale phylogenetic analyses. Bioinformatics 25:1972-1973.

Celton, J., S. Martinez, M. Jammes, A. Bechti, S. Salvi, J. Legave, and E. Costes. 2011. Deciphering the genetic determinism of bud phenology in apple progenies: A new insight into chilling and heat requirement effects on flowering dates and positional candidate genes. New Phytol. 192:378-392.

Che, P., S. Lall, D. Nettleton, and S.H. Howell. 2006. Gene expression programs during shoot, root, and callus development in arabidopsis tissue culture. Plant Physiol. 141:620-637.

Colquhoun, T.A. and D.G. Clark. 2011. Unraveling the regulation of floral fragrance biosynthesis. Plant Signal. Behav. 6:378-381.

Cooke, J., M. Eriksson, and O. Junttila. 2012. The dynamic nature of bud dormancy in trees: Environmental control and molecular mechanisms. Plant Cell Environ. 35:1707-1728.

Daccord, N., J-M. Celton, G. Linsmith, C. Becker, N. Choisne, E. Schijlen, H. van de Geest, L. Bianco, D. Micheletti, R. Velasco, E. A. Di Pierro, J. Gouzy, D.J.G. Rees, P. Guérif, H. Muranty, C-E. Durel, F. Laurens, Y. Lespinasse, S. Gaillard, S. Aubourg, H. Quesneville, D. Weigel, E. van de Weg, M. Troggio, and E. Bucher. 2017. High-quality de novo assembly of the apple genome and methylome dynamics of early fruit development. Nat. Genet. 49:1099-1106.

Doğramaci, D., D. Horvath, and J. Anderson. 2014. Dehydrationinduced endodormancy in crown buds of leaf spurge highlights involvement of MAF3- and RVE1-like homologs, and hormone signaling cross-talk. Plant Mol. Biol. 86:409-424.

Du, X., Q. Xiao, R. Zhao, F. Wu, Q. Xu, K. Chong, and Z. Meng. 2008. TrMADS3, a new MADS-box gene, from a perennial species Taihangia rupestris (Rosaceae) is upregulated by cold and experiences seasonal fluctuation in expression level. Dev. Genes Evol. 218:281-292.

Fan, S., D. Bielenberg, T. Zhebentyayeva, G. Reighard, W. Okie, D. Holland, and A. Abbott. 2010. Mapping quantitative trait loci associated with chilling requirement, heat requirement and bloom date in peach (Prunus persica). New Phytol. 185:917-930.

Faust, M., D. Liu, S. Wang, and G. Stutte. 1995. Involvement of apical dominance in winter dormancy of apple buds. Acta Hort. 395:47-56.

Franklin, K.A., S.H. Lee, D. Patel, S.V. Kumar, A.K. Spartz, C. Gu, S. Ye, P. Yu, G. Breen, J.D. Cohen, P.A. Wigge, and W.M. Gray. 2011. Phytochrome-interacting factor 4 (PIF4) regulates auxin biosynthesis at high temperature. Proc. Natl. Acad. Sci. USA 108:20231-20235.

Gangappa, S., S. Berriri, and S.V. Kumar. 2017. PIF4 coordinates thermosensory growth and immunity in arabidopsis. Curr. Biol. 27:243-249.

Goossens, J., G. Swinnen, R. Vanden Bossche, L. Pauwels, and A. Goossens. 2015. Change of a conserved amino acid in the MYC2 and MYC3 transcription factors leads to release of JAZ repression and increased activity. New Phytol. 206:1229-1237.

Hauagge, R. and J. Cummins. 1991. Phenotypic variation of length of bud dormancy in apple cultivars and related Malus species. J. Amer. Soc. Hort. Sci. 116:100-106.

Heide, O. and A. Prestrud. 2005. Low temperature, but not photoperiod, controls growth cessation and dormancy induction and release in apple and pear. Tree Physiol. 25:109-114.

Horvath, D., W. Chao, J. Suttle, J. Thimmapuram, and J. Anderson. 2008. Transcriptome analysis identifies novel responses and potential regulatory genes involved in seasonal dormancy transitions of leafy spurge (Euphorbia esula L.). BMC Genomics 9:1-17.

Hsu, C-Y., J.P. Adams, H. Kim, K. No, C. Ma, S.H. Strauss, J. Drnevich, L. Vandervelde, J.D. Ellis, B.M. Rice, N. Wickett, L.E. Gunter, G.A. Tuskan, A.M. Brunner, G.P. Page, A. Barakat, J.E. Carlson, C.W. dePamphilis, D.S. Luthe, and C. Yuceer. 2011. FLOWERING LOCUS T duplication coordinates reproductive and vegetative growth in perennial poplar. Proc. Natl. Acad. Sci. USA 108:10756-10761.

Ito, A., T. Saito, D. Sakamoto, T. Sugiura, S. Bai, and T. Moriguchi. 2016. Physiological differences between bud breaking and flowering after dormancy completion revealed by DAM and FT/TFL1 expression in Japanese pear (Pyrus pyrifolia). Tree Physiol. 36:109-120. 
John, R., N.A. Anjum, S.K. Sopory, N.A. Akram, and M. Ashraf. 2016. Some key physiological and molecular processes of cold acclimation. Biol. Plant. 60:603-618.

Katoh, K. and D. Standley. 2013. MAFFT multiple sequence alignment software version 7: Improvements in performance and usability. Mol. Biol. Evol. 30:772-780.

Kazan, K. and J.M. Manners. 2013. MYC2: The master in action. Mol. Plant 6:686-703.

Khalil-Ur-Rehman, M., L. Sun, C.X. Li, M. Faheem, W. Wang, and J.M. Tao. 2017. Comparative RNA-seq based transcriptomic analysis of bud dormancy in grape. BMC Plant Biol. 17:18.

Kitamura, Y., T. Takeuchi, H. Yamane, and R. Tao. 2016. Simultaneous down-regulation of DORMANCY-ASSOCIATED MADS-box6 and SOC1 during dormancy release in Japanese apricot (Prunus mume) flower buds. J. Hort. Sci. Biotechnol. 91:476-482.

Kumar, G., P. Arya, L. Gupta, V. Randhawan, V. Acharya, and A. Singh. 2016a. Comparative phylogenetic analysis and transcriptional profiling of MADS-box gene family identified DAM and FLC-like genes in apple (Malus $\times$ domestica). Sci. Rpt. 6:20695.

Kumar, G., K. Gupta, S. Pathania, M.K. Swarnkar, U.K. Rattan, G. Singh, R.K. Sharma, and A.K. Singh. 2017. Chilling affects phytohormone and post-embryonic development pathways during bud break and fruits set in apple (Malus domestica Borkh.). Sci. Rpt. 7:42593

Kumar, S., G. Stecher, and K. Tamura. 2016b. MEGA7: Molecular evolutionary genetics analysis version 7.0 for bigger datasets. Mol. Biol. Evol. 33:1870-1874.

Labuschagné, I., B. Louw, K. Schmidt, and A. Sadie. 2002. Genotypic variation in prolonged dormancy symptoms in apple progenies. HortScience 37:157-163.

Lang, G. 1987. Dormancy: A new universal terminology. HortScience 22:817-820.

Lang, G., J. Early, G. Martin, and R. Darnell. 1987. Endo, para-, and ecodormancy: Physiological terminology and classification for dormancy research. HortScience 22:371-377.

Leida, C., A. Conesa, G. Llácer, M. Badenes, and G. Ríos. 2012. Histone modifications and expression of DAM6 gene in peach are modulated during bud dormancy release in a cultivar-dependent manner. New Phytol. 193:67-80.

Li, H. and R. Durbin. 2009. Fast and accurate short read alignment with Burrows-Wheeler transform. Bioinformatics 25:1754-1760.

Li, Z., G. Reighard, A. Abbott, and D. Bielenberg. 2009. Dormancyassociated MADS genes from the EVG locus of peach [Prunus persica (L.) Batsch] have distinct seasonal and photoperiodic expression patterns. J. Expt. Bot. 60:3521-3530.

Liu, G., W. Li, P. Zheng, T. Xu, L. Chen, D. Liu, S. Hussain, and Y. Teng. 2012. Transcriptomic analysis of 'Suli' pear (Pyrus pyrifolia white pear group) buds during the dormancy by RNA-seq. BMC Genomics 13:700.

Maurya, J. and R. Bhalerao. 2017. Photoperiod- and temperaturemediated control of growth cessation and dormancy in trees: A molecular perspective. Ann. Bot. 120:351-360.

Mazzitelli, L., R. Hancock, S. Haupt, P. Walker, S. Pont, J. McNicol, L. Cardle, J. Morris, R. Viola, R. Brennan, P. Hedley, and M. Taylor. 2007. Co-ordinated gene expression during phases of dormancy release in raspberry (Rubus idaeus L.) buds. J. Expt. Bot. 58:10351045.

Mimida, N., T. Saito, T. Moriguchi, A. Suzuki, S. Komori, and M. Wada. 2015. Expression of DORMANCY-ASSOCIATED MADS$B O X(D A M)$-like genes in apple. Biol. Plant. 59:237-244.

$\mathrm{Ng}, \mathrm{M}$. and M. Yanofsky. 2001. Function and evolution of the plant MADS-box gene family. Nat. Rev. Genet. 2:186-195.

Olsen, J. 2010. Light and temperature sensing and signaling in induction of bud dormancy in woody plants. Plant Mol. Biol. 73:37-47.

Pařenicová, L., S. de Folter, M. Kieffer, D. Horner, C. Favalli, J. Busscher, H. Cook, R. Ingram, M. Kater, B. Davies, G. Angenent, and L. Colombo. 2003. Molecular and phylogenetic analyses of the complete MADS-box transcription factor family in arabidopsis new openings to the MADS world. Plant Cell 15:1538-1551.

Pérez, F., N. Kühn, and R. Vergara. 2011. Expression analysis of phytochromes A, B and floral integrator genes during the entry and exit of grapevine-buds from endodormancy. J. Plant Physiol. 168:1659-1666.

Petri, J. and G. Leite. 2004. Consequences of insufficient winter chilling on apple tree bud-break. Acta Hort. 662:53-60.

Porto, D., M. Bruneau, P. Perini, R. Anzanello, J-P. Renou, H. dos Santos, F. Fialho, and L. Revers. 2015. Transcription profiling of the chilling requirement for bud break in apples: A putative role for FLC-like genes. J. Expt. Bot. 66:2659-2672.

Porto, D., V. da Silveira Falavigna, R. Arenhart, P. Perini, V. Buffon, R. Anzanello, H. dos Santos, F. Fialho, P. de Oliveira, and L. Revers. 2016. Structural genomics and transcriptional characterization of the Dormancy-Associated MADS-box genes during bud dormancy progression in apple. Tree Genet. Genomes 12:1-15.

Richardson, E., S. Seeley, and D. Walker. 1974. A model for estimating the completion of rest for Redhaven and Elberta peach trees. HortScience 9:331-332.

Rinne, P.L., A. Welling, J. Vahala, L. Ripel, R. Ruonala, J. Kangasjärvi, and C. van der Schoot. 2011. Chilling of dormant buds hyperinduces FLOWERING LOCUS T and recruits GA-inducible 1, 3 - $\beta$-glucanases to reopen signal conduits and release dormancy in Populus. Plant Cell 23:130-146.

Rinne, P., A. Welling, and C. van der Schoot. 2010. Perennial life style of Populus: Dormancy cycling and overwintering, p. 171-200. In: S. Jansson, R.P. Bhalerao, and A.T. Groover (eds.). Genetics and genomics of Populus. Springer, New York, NY.

Rohde, A. and R. Bhalerao. 2007. Plant dormancy in the perennial context. Trends Plant Sci. 12:217-223.

Rohde, A., V. Storme, V. Jorge, M. Gaudet, N. Vitacolonna, F. Fabbrini, T. Ruttink, G. Zaina, N. Marron, S. Dillen, M. Steenackers, M. Sabatti, M. Morgante, W. Boerjan, and C. Bastien. 2011. Bud set in poplar-Genetic dissection of a complex trait in natural and hybrid populations. New Phytol. 189:106-121.

Ruttink, T., M. Arend, K. Morreel, V. Stome, S. Rombauts, J. Fromm, R. Bhalerao, W. Boerjan, and A. Rohde. 2007. A molecular timetable for apical bud formation and dormancy induction in poplar. Plant Cell 19:2370-2390.

Saito, T., S. Bai, A. Ito, D. Sakamoto, T. Saito, B. Ubi, T. Imai, and T. Moriguchi. 2013. Expression and genomic structure of the dormancyassociated MADS box genes MADS13 in Japanese pears (Pyrus pyrifolia Nakai) that differ in their chilling requirement for endodormancy release. Tree Physiol. 33:654-667.

Sasaki, R., H. Yamane, T. Ooka, H. Jotatsu, Y. Kitamura, T. Akagi, and R. Tao. 2011. Functional and expressional analyses of PmDAM genes associated with endodormancy in Japanese apricot. Plant Physiol. 157:485-497.

Saure, M. 1985. Dormancy release in deciduous fruit trees. Hort. Rev. 7:239-300.

Sugiura, T., H. Kuroda, and H. Sugiura. 2007. Influence of the current state of global warming on fruit tree growth in Japan. Hort. Res. (Japan) 6:257-263. (In Japanese with English summary).

Tian, Y., Q. Dong, Z. Ji, F. Chi, P. Cong, and Z. Zhou. 2015. Genomewide identification and analysis of the MADS-box gene family in apple. Gene 555:277-290.

Ubi, B., D. Sakamoto, Y. Ban, T. Shimada, A. Ito, I. Nakajima, Y. Takemura, F. Tamura, T. Saito, and T. Moriguchi. 2010. Molecular cloning of dormancy-associated MADS-box gene homologs and their characterization during seasonal endodormancy transitional phases of Japanese pear. J. Amer. Soc. Hort. Sci. 135:174-182.

Urrestarazu, J., H. Muranty, C. Denancé, D. Leforestier, E. Ravon, A. Guyader, R. Guisnel, L. Feugey, S. Aubourg, J-M. Celton, N. Daccord, L. Dondini, R. Gregori, M. Lateur, P. Houben, M. Ordidge, F. Paprstein, J. Sedlak, H. Nybom, L. Garkava-Gustavsson, M. Troggio, L. Bianco, R. Velasco, C. Poncet, A. Théron, S. Moriya, M.C.A.M. Bink, F. Laurens, S. Tartarini, and C-E. Durel. 2017. 
Genome-wide association mapping of flowering and ripening periods in apple. Front. Plant Sci. 8:1923.

van Dyk, M., M. Soeker, I. Labuschagne, and D. Rees. 2010. Identification of a major QTL for time of initial vegetative budbreak in apple (Malus $\times$ domestica Borkh.). Tree Genet. Genomes 6:489-502.

Velasco, R., A. Zharkikh, J. Affourtit, A. Dhingra, A. Cestaro, A. Kalyanaraman, P. Fontana, S.K. Bhatnagar, M. Troggio, D. Pruss, S. Salvi, M. Pindo, P. Baldi, S. Castelletti, M. Cavaiuolo, G. Coppola, F. Costa, V. Cova, A.D. Ri, V. Goremykin, M. Komjanc, S. Longhi, P. Magnago, G. Malacarne, M. Malnoy, D. Micheletti, M. Moretto, M. Perazzolli, A. Si-Ammour, S. Vezzulli, E. Zini, G. Eldredge, L.M. Fitzgerald, N. Gutin, J. Lanchbury, T. Macalma, J.T. Mitchell, J. Reid, B. Wardell, C. Kodira, Z. Chen, B. Desany, F. Niazi, M. Palmer, T. Koepke, D. Jiwan, S. Schaeffer, V. Krishnan, C. Wu, V.T. Chu, S.T. King, J. Vick, Q. Tao, A. Mraz, A. Stormo, K. Stormo, R. Bogden, D. Ederle, A. Stella, A. Vecchietti, M.M. Kater, S. Masiero, P. Lasserre, Y. Lespinasse, A.C. Allan, V. Bus, D. Chagné, R.N. Crowhurst, A.P. Gleave, E. Lavezzo, J.A. Fawcett, S. Proost, P. Rouzé, L. Sterck, S. Toppo, B. Lazzari, R.P. Hellens, C-E. Durel, A. Gutin, R.E. Bumgarner, S.E. Gardiner, M. Skolnick, M. Egholm, Y. Van de Peer, F. Salamini, and R. Viola. 2010. The genome of the domesticated apple (Malus $\times$ domestica Borkh.). Nat. Genet. 42:833-839.

Wang, S.Y., H.J. Jiao, and M. Faust. 1991. Changes in metabolic enzyme activities during thidiazuron-induced lateral budbreak of apple. HortScience 26:171-173.

Wisniewski, M., J. Norelli, and T. Artlip. 2015. Overexpression of a peach CBF gene in apple: A model for understanding the integration of growth, dormancy, and cold hardiness in woody plants. Front. Plant Sci. 6:85.

Wu, R., S. Tomes, S. Karunairetnam, S. Tustin, R. Hellens, A. Allan, R. Machnight, and E. Varkonyi-Gasic. 2017. SVP-like MADS-box genes control dormancy and budbreak in apple. Front. Plant Sci. 8:477.
Wu, R-M., E. Walton, A. Richardson, M. Wood, R. Hellens, and E. Varkonyi-Gasic. 2012. Conservation and divergence of four kiwifruit $S V P$-like MADS-box genes suggest distinct roles in kiwifruit bud dormancy and flowering. J. Expt. Bot. 63:797807.

Yamane, H., Y. Kashiwa, T. Ooka, R. Tao, and K. Yonemori. 2008. Suppression subtractive hybridization and differential screening reveals endodormancy-associated expression of an SVP/AGL24-type MADS-box gene in lateral vegetative buds of Japanese apricot. J. Amer. Soc. Hort. Sci. 133:708-716.

Yamane, H., T. Ooka, H. Jotatsu, Y. Hosaka, R. Sasaki, and R. Tao. 2011a. Expressional regulation of Pp2DAM5 and PpDAM6, peach (Prunus persica) dormancy-associated MADS-box genes, by low temperature and dormancy-breaking reagent treatment. J. Expt. Bot. 62:3481-3488.

Yamane, H., T. Takeuchi, M. Matsushita, K. Banno, and R. Tao. 2018. Expression analysis of apple $D A M \mathrm{~s}$ in 'Fuji' dormant flower buds during flower bud development. Acta Hort. (In press).

Yamane, H., R. Tao, T. Ooka, H. Jotatsu, R. Sasaki, and K. Yonemori. 2011b. Compapative analyses of dormancy-associated MADS-box genes, PpDAM5 and PpDAM6, in low- and high-chill peaches (Prunus persica L.). J. Jpn. Soc. Hort. Sci. 80:276-283.

Young, M.D., M.J. Wakefield, G.K. Smyth, and A. Oshlack. 2010. Gene ontology analysis for RNA-seq: Accounting for selection bias. Genome Biol. 11:R14.

Zhang, J-Z., Z-M. Li, L. Mei, J-L. Yao, and G-G. Hu. 2009. PtFLC homolog from trifoliate orange (Poncirus trifoliata) is regulated by alternative splicing and experiences seasonal fluctuation in expression level. Planta 229:847-859.

Zhu, Y., Y. Li, D. Xin, W. Chen, X. Shao, Y. Wang, and W. Guo. 2015. RNA-seq-based transcriptome analysis of dormant flower buds of chinese cherry (Prunus pseudocerasus). Gene 555:362-376. 